\title{
Development of the Sci-math Sensemaking Framework: categorizing sensemaking of mathematical equations in science
}

\author{
FangFang Zhao ${ }^{1}$ and Anita Schuchardt ${ }^{2 *}$ (D)
}

\begin{abstract}
Scientific ideas are often expressed as mathematical equations. Understanding the ideas contained within these equations requires making sense of both the embedded mathematics knowledge and scientific knowledge. Students who can engage in this type of blended sensemaking are more successful at solving novel or more complex problems with these equations. However, students often tend to rely on algorithmic/procedural approaches and struggle to make sense of the underlying science. This deficit may partly be the fault of instruction that focuses on superficial connections with the science and mathematics knowledge such as defining variables in the equation and demonstrating step-by-step procedures for solving problems. Research into the types of sensemaking of mathematical equations in science contexts is hindered by the absence of a shared framework. Therefore, a review of the literature was completed to identify themes addressing sensemaking of mathematical equations in science. These themes were compiled into nine categories, four in the science sensemaking dimension and five in the mathematics sensemaking dimension. This framework will allow for comparison across studies on the teaching and learning of mathematical equations in science and thus help to advance our understanding of how students engage in sensemaking when solving quantitative problems as well as how instruction influences this sensemaking.
\end{abstract}

Keywords: Sensemaking, Equation, Science, Mathematics

\section{Introduction}

Mathematical equations are used to represent scientific phenomenon and communicate scientific ideas (Bialek \& Botstein, 2004; Brush, 2015; Gingras, 2001; Lazenby \& Becker, 2019; Steen, 2005). Students are expected to be able to engage in sensemaking with these equations to interpret the mathematical and scientific meaning represented by the equation (Bialek \& Botstein, 2004; Heisterkamp \& Talanquer, 2015; Kuo, Hull, Gupta, \& Elby, 2013; Sevian \& Talanquer, 2014). However, studies on students solving quantitative problems show that they often solve problems by relying on algorithmic

\footnotetext{
* Correspondence: aschucha@umn.edu

${ }^{2}$ Department of Biology Teaching and Learning, College of Biological Sciences, University of Minnesota-Twin Cities, 5-210H Moos Tower, 515

Delaware Street, SE, Minneapolis, MN 55455, USA

Full list of author information is available at the end of the article
}

procedures without making connections between the mathematical equation and the scientific phenomenon (Bing \& Redish, 2009; Stewart, 1983; Taasoobshirazi \& Glynn, 2009; Tuminaro \& Redish, 2007). This tendency to solve problems algorithmically has been associated with a failure to transfer problem-solving techniques to novel contexts or more complex problems (Becker \& Towns, 2012; Nakhleh, 1993; Ralph \& Lewis, 2018; Schuchardt \& Schunn, 2016; Stamovlasis, Tsaparlis, Kamilatos, Papaoikonomou, \& Zarotiadou, 2005). The reliance on algorithmic problem-solving strategies has been attributed to the different opportunities provided for sensemaking of mathematical equations in science during instruction (Bing \& Redish, 2008; Lythcott, 1990; Schuchardt \& Schunn, 2016). To successfully develop and understand the impact of providing different 
sensemaking opportunities, it is first necessary to understand the types of sensemaking that can occur. However, a consistent and coherent framework of sensemaking of mathematical equations in science has not yet been developed. This paper presents such a framework based on a review of the literature on instruction of mathematical equations in science and on students' problem-solving using mathematical equations in a science context.

\section{Scientists use mathematical knowledge to represent ideas about scientific phenomenon}

Canonical mathematical equations in science have been developed based on understanding of both scientific phenomena and mathematical concepts represented in the equations (Ghosh, 2009; Quale, 2011). Scientists use mathematical equations to formulate theories deduced from observations or experimentation or to represent patterns they observe (Brush, 2015; de Ataíde \& Greca, 2013; De Berg, 1992; Ghosh, 2009; Pospiech, 2019; Steen, 2005; Wigner, 1960). For example, Newton's second law of motion is often represented as $\vec{F}_{n e t}=m \vec{a}$. The development of $\vec{F}_{n e t}=m \vec{a}$ was based on observations from multiple scientists, as well as many experiments in making sense of the scientific phenomenon (Ghosh, 2009). The equation represents a "central principle of classical mechanics" (Gierer, 2004), a theory that has been used to explain the motions of objects. In biology, the mathematical expression for the population growth of bacteria in optimal growth conditions $N_{t}=$ $N_{0} 2^{x}$ is based on scientists' biological knowledge of the relationship among the initial population size $\left(N_{0}\right)$, the number of generations $(x)$, and the final population size $\left(N_{t}\right)$ after a specific time period. This biological understanding was combined with knowledge of how to arrange the mathematical variables and mathematical operations (i.e., multiplication, exponents) to match the quantitative relationships to the patterns found in the phenomenon. Whether equations are developed to represent a theory or a pattern, both scientific knowledge and mathematical knowledge are embedded in these equations.

Mathematical equations are often referred to as models of scientific phenomena, "a representation of structure in a physical system or process" (Hestenes, 2010, p. 18). The development of mathematical models of scientific phenomena as engaged in by scientists is a multi-faceted, multi-step process known as the modeling cycle (Diaz Eaton et al., 2019; Gouvea \& Passmore, 2017; Halloun, 2007; Hestenes, 2010). The steps in the modeling cycle include identifying the task or relations to be represented, mathematizing the physical entities, structuring the equation to express the pattern, interpreting the equation with reference to the scientific process, and validating the equation (Borromeo Ferri, 2006; Dukerich, 2015; Gouvea \& Passmore, 2017; Redish, 2017). If the mathematical model is validated in one situation, the process is repeated in other situations. If the model is not found to match the data, either the idea is rejected or the model is modified (Halloun, 2007; Hestenes, 2010). The modeling process as engaged in by scientists provides multiple opportunities for making sense of the connections between the mathematical equation, the phenomenon, and the mathematical ideas.

Three theoretical perspectives have been widely used when investigating students' ability to solve quantitative problems in science; the resources framework (diSessa, 1993; Hammer, 2000; Redish \& Kuo, 2015; Rodriguez, Bain, Hux, \& Towns, 2019), epistemological framing (Bing \& Redish, 2012; Chen, Irving, \& Sayre, 2013; Hammer, Elby, Scherr, \& Redish, 2005; Hutchison \& Hammer, 2009; Redish, 2004; Tuminaro \& Redish, 2007), and sensemaking (Becker \& Towns, 2012; Bing \& Redish, 2007; Dreyfus, Elby, Gupta, \& Sohr, 2017; Eichenlaub \& Redish, 2019; Kuo et al., 2013; Sherin, 2001). The resource perspective examines how and what cognitive resources are activated in the problem-solving process (Hammer, 2000; Redish \& Kuo, 2015). Studies guided by epistemological framing focus on how students perceive mathematics in science and solving quantitative problems in science classrooms as well as how students' framing affects problem-solving (Chen et al., 2013; Tuminaro \& Redish, 2007). Sensemaking is broadly defined as using prior resources and knowledge to understand new concepts or representations or to solve problems (Kapon, 2016; Martin \& Kasmer, 2009; Schoenfeld, 1992). With respect to mathematical equations in science, students need to make sense of both the mathematical structure of the equation (Sherin, 2001) and the connections to the scientific phenomenon (Redish, 2017; Schuchardt \& Schunn, 2016). These three perspectives are not mutually exclusive. The resources that a student activates are likely influenced by their epistemological framing (Hammer et al., 2005; Redish \& Kuo, 2015). The resources that are activated are likely to affect sensemaking (Dreyfus et al., 2017).

\section{Blended sensemaking as a lens for investigating students' quantitative problem-solving}

Blended sensemaking is described as the process of combining separate cognitive resources to generate a new merged, blended understanding (Fauconnier \& Turner, 1998). Scientific knowledge and mathematical knowledge are two cognitive resources that can be activated during sensemaking of mathematical equations that describe scientific phenomena. The sensemaking of these equations can occur with respect to only scientific ideas or only mathematical ideas if only one of these resources is 
activated, or sensemaking can be blended, making use of both cognitive resources (Bain, Rodriguez, Moon, \& Towns, 2019; Eichenlaub \& Redish, 2019). For example, in the sensemaking of $\vec{F}_{n e t}=m \vec{a}$, the resources from mathematics (e.g., procedures of doing calculation, knowledge of multiplication, knowledge of the mathematics notation) can be blended with resources from science (e.g. the net force causes the acceleration) and together form a blended mental space that enables proper interpretation and application of this equation. Experts' understanding of physics equations includes the blending of mathematical forms and physical intuition, but novices tend to treat mathematical equations as a calculation tool without connection to the physics knowledge (Eichenlaub \& Redish, 2019). In the above equation, the vector notation above the " $F$ " and the " $a$ " has mathematical meaning indicating that those quantities have direction. This mathematical understanding can be combined with the physics knowledge that acceleration will occur in the same direction as the net force. After receiving instruction in Newton's second law, undergraduate physics students were asked to solve two problems related to this topic. Many students failed to access their scientific and mathematics resources and showed difficulty in understanding the directionality embedded in the equation (Flores-García, Terrazas, González-Quezada, Pierce, \& Soto, 2008). Students often fail to access both of these resources and thus often do not pay attention to the directionality embedded in the equation (Flores-García et al., 2008).

Categorization of blended sensemaking has been used to describe students' quantitative problem-solving (Bain, Rodriguez, Moon, \& Towns, 2018; Bain, Rodriguez, Moon, \& Towns, 2019; Bing \& Redish, 2007, 2009; Brahmia, Boudreaux, \& Kanim, 2016; Greca \& Moreira, 2002; $\mathrm{Hu}$ \& Rebello, 2013; Kuo et al., 2013; Tuminaro \& Redish, 2007). Bing and Redish (2007) identified two types of blending in students' problem-solving processes, single-scope blend (a one-way mapping) and doublescope blend (a back-and-forth integration). The difference between these two types of blending lies in whether the sensemaking uses only one cognitive resource or moves back and forth between the science and mathematics cognitive resources. In one study (Bing \& Redish, 2007), when students were reasoning about the direction of air drag for falling objects using the equation $F_{v}=-$ $b v$, they started their sensemaking of the equation in the physics space, mapping the variables onto aspects of the scientific phenomenon, and then used their physics knowledge to reason that friction $\left(F_{v}\right)$ operates in the opposite direction of velocity $(v)$. They then discussed the mathematical rule that multiplying two negatives together yields a positive outcome. Finally, they showed a blending of the knowledge from physics and mathematics when they reasoned that positive is up, and therefore, the direction of friction for falling objects is up (Bing \& Redish, 2007). In chemistry, students were found to make sense of equations starting from either a chemistry or mathematics space and then pull in concepts from the other discipline to complete the problem-solving process (Bain, Rodriguez, Moon, \& Towns, 2019). These authors proposed that the quality of blended sensemaking was dependent on whether students applied a superficial or sophisticated conceptual understanding in chemistry space. However, details were not provided on what kind of conceptual understanding should be considered as superficial or sophisticated, or on the difference between low and high quality blended sensemaking. This study aims to provide a lessevaluative framework for examining sensemaking that provides rich descriptions of the types of sensemaking that are occurring in both the mathematics and science dimensions. The definition and examples used to explain each type of sensemaking will enable consistent descriptions for sensemaking that can then be evaluated based on additional criteria.

Students' difficulties with quantitative problem-solving have been attributed to difficulties with making sense of the conceptual knowledge embedded in the mathematical equations (Bing \& Redish, 2007, 2009; Schuchardt \& Schunn, 2016; Tuminaro \& Redish, 2007). In physics, chemistry, and biology, students struggle to apply mathematical equations they have learned in class to novel or more complex scenarios (Becker \& Towns, 2012; Nakhleh, 1993; Ralph \& Lewis, 2018; Schuchardt \& Schunn, 2016; Stamovlasis et al., 2005). This difficulty has been attributed to students' tendency to apply memorized algorithmic procedures instead of making sense of connections between the mathematical equations and the modeled scientific phenomenon (Bing \& Redish, 2009; Stewart, 1983; Taasoobshirazi \& Glynn, 2009; Tuminaro \& Redish, 2007). When students spontaneously apply blended sensemaking, they are able to overcome being stuck and solve more complex problems (Bing \& Redish, 2007; Kuo et al., 2013). One instructional approach that provides opportunities for students to connect the scientific phenomenon to the mathematics is model-based instruction (Blum \& Borromeo, 2009). If instruction encourages engagement in mathematical modeling and sensemaking, students show improved quantitative problem-solving for novel and more complex problems (Becker, Rupp, \& Brandriet, 2017; Lazenby \& Becker, 2019; Schuchardt \& Schunn, 2016).

\section{Viewing instruction of mathematics in science through the lens of blended sensemaking}

Sensemaking opportunities provided by the instructors in the classroom serve a critical role in students' learning 
(Koretsky, Keeler, Ivanovitch, \& Cao, 2018; Li \& Schoenfeld, 2019; Lo, Marton, Pang, \& Pong, 2004; Marton, Runesson, \& Tsui, 2004). What the instructor does and says create the opportunities or the environment for students to make sense of something, i.e., the conditions for students to learn specific content or skills (Marton et al., 2004). Mathematics instruction in the USA has been criticized as "broad and shallow" (Polikoff, 2012), focusing on procedures without connection to mathematical concepts (Litke, 2020). Teachers in countries whose students do well on mathematical assessments tend to focus more on conceptual understanding than procedures (Hill, Rowan, \& Ball, 2005). Science instruction that focuses on high-level thinking (e.g., doing scientific inquiry) as compared to low-level thinking (e.g., rote memorization) is also associated with better learning outcomes for students (Tekkumru-Kisa, Stein, \& Schunn, 2015). Besides the effect on students' learning outcomes, instruction also affects students' perception of what is valued in science learning and their understanding of the nature of scientific knowledge (Bing \& Redish, 2009; Eichenlaub \& Redish, 2019; Hutchison \& Hammer, 2009; Kang, Windschitl, Stroupe, \& Thompson, 2016; Russ, 2018; Russ, Coffey, Hammer, \& Hutchison, 2009; Tuminaro \& Redish, 2007). For example, evaluation in introductory physics courses tends to focus on students' correct calculation rather than their understanding of the meaning of the equations (Eichenlaub \& Redish, 2019). In this instructional environment, students can develop the belief that mathematics is merely a tool to do calculation in physics, and they may devalue conceptual understanding of mathematical equations.

Instructional opportunities for student sensemaking of equations are not necessarily synonymous with specific teaching practices. For example, although making sense of mathematical rules often occurs through instructors delivering explanations via lecture (Njini, 2012), Baig and Halai (2006) presented a student-centered learning activity to make sense of four rules for working with fractions. Marton et al. (2004) argued that the understanding of what learners are expected to learn needs to occur before an effective teaching method can be identified. However, attention is rarely paid to the sensemaking opportunities created by what the instructor is doing or saying.

Many frameworks or protocols have been proposed to describe or measure instructional practice or discourse in mathematics or science classrooms, e.g., Classroom Observation Protocol for Undergraduate STEM (Smith, Jones, Gilbert, \& Wieman, 2013), Classroom Discourse Observation Protocol (Kranzfelder et al., 2019), Instructional Quality Assessment (Boston, 2012), Mathematical Quality of Instruction (Learning Mathematics for Teaching Project, 2011), and Reformed-Oriented Teaching
Observation Protocol (Sawada et al., 2002). Very few frameworks specifically discuss instruction of mathematics in science classrooms. One framework that has been developed is the Mathematics Integrated into Science: Classroom Observation Protocol, MISCOP (Judson, 2013). This framework seeks to characterize the extent of integration of mathematics and science and the overall quality of instruction to evaluate the quality of integration of mathematics in science. The opportunities for student sensemaking of mathematical equations in science provided by instructors are not addressed.

This paper establishes the Sci-Math Sensemaking Framework for categorizing sensemaking of mathematical equations in science on the science and mathematics dimensions. Categories within the framework are identified based on a literature review using manuscripts from both the science education and mathematics education communities. This framework supplies researchers with a common language for discussing opportunities instructors provide for sensemaking of mathematical equations in science as well as student use of sensemaking when working with these equations.

\section{Methods}

The objective for this literature review is to identify ideas expressed in the literature about the different types of mathematics sensemaking and science sensemaking of mathematical equations in science. A snowballing approach that began with recent reviews of the literature was used (Wohlin, 2014). The procedure is shown in Fig. 1 and includes identification of an initial set of manuscripts, a backward screening on the reference lists of the starting set of manuscripts, a forward screening on the publications citing the starting set of manuscripts, and iteration of backward and forward screening on the included publications (Wohlin, 2014).

\section{Identifying the starting set of manuscripts}

Guided by the theory of blended sensemaking of mathematical equations in science, five topics from the field of education research were chosen to search for the starting set of manuscripts (Table 1). Three of the topics covered mathematics in three science fields commonly taught in schools: chemistry, biology, and physics. Mathematics sensemaking and science sensemaking were the other two topics to provide publications that discussed sensemaking in each discipline. Within each topic, the starting set of manuscripts was identified using a key word search in Google Scholar or based on recommendations from experts. When more than one reference was identified through these methods, the publications that contained the greatest number of citations were retained to provide breadth and depth of literature in the initial backward snowballing. Out of these, the most 


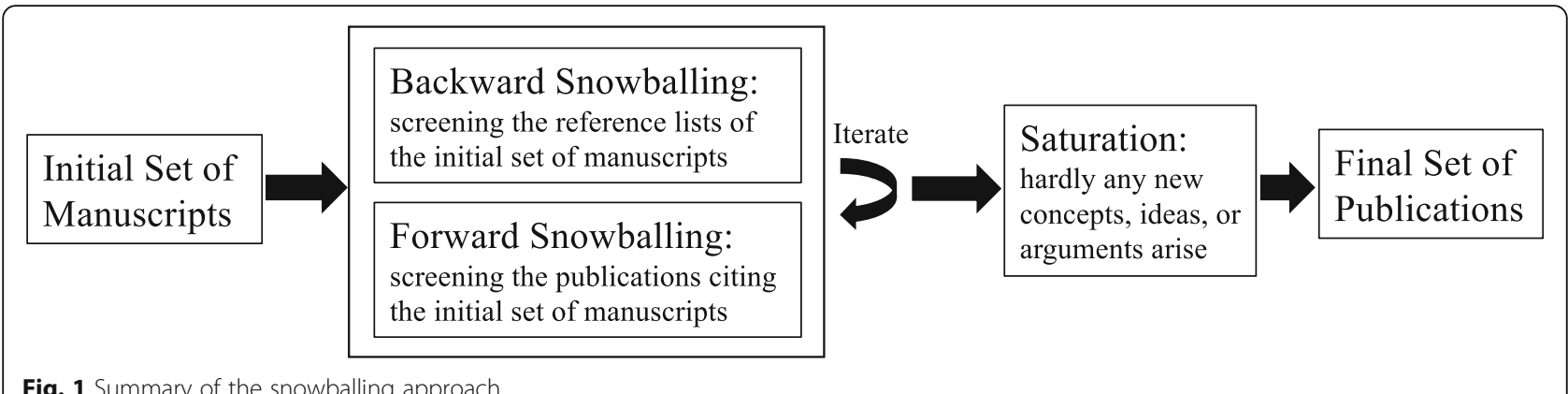

Fig. 1 Summary of the snowballing approach

recent manuscript was chosen in each topic area to uncover the most recent publications in the field. Five manuscripts published during 2015-2019 were identified that cover the following topics: (a) mathematics in physics, (b) mathematics in chemistry, (c) mathematics in biology, (d) science sensemaking, and (e) mathematics sensemaking (Table 1).

\section{Iteration 1}

\section{Backward snowballing}

For each of the five starting manuscripts, the publications listed in the references were screened based on the following inclusion and exclusion criteria. The inclusion criteria were: published between 1986 and 2019; written in English; included components of mathematical knowledge of equations or scientific knowledge with respect to equations; and published papers, conference proceedings, book chapters, or dissertations. The exclusion criteria were: published earlier than 1986, a whole book, written in a non-English language, not about mathematical equations, provided only a broad description of teaching strategies or student problem-solving abilities or student epistemologies, not focused on mathematical equations, and from the same research group referring to the same theories and findings as other references. The foundational research symposium on mathematical sensemaking (Hiebert \& Lefevre, 1986) was published in 1986, and research in mathematics in science emerged after research in mathematics education. Therefore, the criterion for publication year was set as

Table 1 Initial set manuscripts and number of publications retained after Iteration 1(I-1) and 2(I-2) snowballing

\begin{tabular}{|c|c|c|c|c|c|}
\hline \multirow[t]{2}{*}{ Topic } & \multirow[t]{2}{*}{ Initial set of manuscripts } & \multirow[t]{2}{*}{ Summary } & \multirow{2}{*}{$\begin{array}{l}\text { Number of } \\
\text { references } \\
\text { cited }\end{array}$} & \multicolumn{2}{|c|}{$\begin{array}{l}\text { Publications } \\
\text { retained }\end{array}$} \\
\hline & & & & $1-1$ & $\mathrm{I}-2$ \\
\hline $\begin{array}{l}\text { Mathematics } \\
\text { in physics }\end{array}$ & $\begin{array}{l}\text { Pospiech, G. (2019). Framework of mathematization } \\
\text { in physics from a teaching perspective. In G. } \\
\text { Pospiech, M. Michelini, \& B. Eylon (Eds.), } \\
\text { Mathematics in physics education (pp. 1-33). }\end{array}$ & $\begin{array}{l}\text { The chapter summarizes the roles of mathematics } \\
\text { in physics and reviews mathematical modeling } \\
\text { and mathematics as a language of physics. }\end{array}$ & 124 & 13 & 3 \\
\hline $\begin{array}{l}\text { Mathematics } \\
\text { in chemistry }\end{array}$ & $\begin{array}{l}\text { Bain, K., Rodriguez, J. M. G., \& Towns, M. H. (2019). } \\
\text { Chemistry and mathematics: Research and } \\
\text { frameworks to explore student reasoning. Journal of } \\
\text { Chemical Education, 96(10), 2086-2096. }\end{array}$ & $\begin{array}{l}\text { The paper reviews frameworks that can guide } \\
\text { research of mathematics in chemical contexts. }\end{array}$ & 104 & 13 & 1 \\
\hline $\begin{array}{l}\text { Mathematics } \\
\text { in biology }\end{array}$ & $\begin{array}{l}\text { Schuchardt, A. M. (2016). Learning biology through } \\
\text { connecting mathematics to scientific mechanisms: } \\
\text { Student outcomes and teacher supports (Order No. } \\
\text { 10298845). Available from ProQuest Dissertations \& } \\
\text { Theses A\&l; ProQuest Dissertations \& Theses Global. } \\
\text { (1847567134). }\end{array}$ & $\begin{array}{l}\text { The dissertation introduces a framework } \\
\text { developed from a literature review categorizing } \\
\text { the ways mathematics is included in science } \\
\text { classrooms. Studies are presented on students' } \\
\text { learning of mathematics in biology. }\end{array}$ & 163 & 10 & 0 \\
\hline $\begin{array}{l}\text { Science } \\
\text { sensemaking }\end{array}$ & $\begin{array}{l}\text { Odden, T. O. B., \& Russ, R. S. (2019). Defining } \\
\text { sensemaking: Bringing clarity to a fragmented } \\
\text { theoretical construct. Science Education, 103(1), 187- } \\
205 .\end{array}$ & $\begin{array}{l}\text { The paper summarizes existing approaches to } \\
\text { describing sensemaking in science education, } \\
\text { defines science sensemaking and distinguishes } \\
\text { sensemaking from other activities in science } \\
\text { education. }\end{array}$ & 79 & 2 & 0 \\
\hline $\begin{array}{l}\text { Mathematics } \\
\text { sensemaking }\end{array}$ & $\begin{array}{l}\text { Rittle-Johnson, B., \& Schneider, M. (2015). } \\
\text { Developing conceptual and procedural knowledge } \\
\text { of mathematics. In Kadosh, R. C., \& Dowker, A. (Eds.) } \\
\text { Oxford Handbook of Numerical Cognition (pp.1118- } \\
\text { 1134). Oxford, United Kingdom: Oxford University } \\
\text { Press. }\end{array}$ & $\begin{array}{l}\text { The chapter reviews studies on the definitions of } \\
\text { and relations between two types of mathematical } \\
\text { knowledge, procedural and conceptual. }\end{array}$ & 100 & 12 & 4 \\
\hline Total & & & & 50 & 8 \\
\hline
\end{tabular}


no earlier than 1986. References were initially screened by title and then abstract. References which remained were read in their entirety to reach the final decision about inclusion. Forty-six references were identified through backwards snowballing.

\section{Forward snowballing}

Forward snowballing was performed on the five manuscripts in the starting set. Citations of each of these manuscripts were located through the "cite" function under Google Scholar. Google Scholar was chosen because of the power of the forward cite function, even though the algorithms for this search tool are not publicized. The multiple iterations of backwards snowballing (screening references listed in identified papers), as well as the use of recent reviews of the literature in five fields to initiate the literature review, mitigate against the danger that some articles may not be included in the review due to bias in the database. The inclusion criteria for forward snowballing were the same as for backward snowballing. Of the five starting manuscripts, the book chapter for mathematics sensemaking (Rittle-Johnson \& Schneider, 2015) has been cited 222 times, the paper of science sensemaking (Odden \& Russ, 2019) has been cited 20 times, the dissertation of mathematics in biology (Schuchardt, 2016) has been cited once, while the book chapter for mathematics in physics (Pospiech, 2019) and the paper of math in chemistry (Bain, Rodriguez, \& Towns, 2019a) have not been cited yet. Because of the recent publication dates for the starting manuscripts, the forward snowballing was not expected to produce many citations. The book chapter for mathematics sensemaking was the most cited but most of the citations are not about knowledge of mathematical equations and thus only four publications were retained from these citations. A total of fifty manuscripts were retained from iteration 1 snowballing (46 from backward snowballing and 4 from forward snowballing).

\section{Iteration 2}

A second iteration of backward and forward snowballing was performed on all 50 publications retained from iteration 1 (see Table S1).

\section{Backward snowballing}

The inclusion criteria for backward snowballing during iteration 2 was the same as during iteration 1 but an additional criterion was added: references had to use a new theoretical framework about mathematical equations to guide their research or analysis. Six publications were identified from the backward snowballing.

\section{Forward snowballing}

Publications that cited any of the 50 manuscripts retained from iteration 1 were identified using Google Scholar. If the citation list for the publication identified in the first iteration contained fewer than 30 cites, all publications were screened by title and abstract and then by reading the whole reference. If the citation list contained more than 30 cites, an initial filtering step was performed using the key words "equation" or "sensemaking," or "blend", or "model." If references contained these keywords, they were then screened one by one using the same criteria as for the backward snowballing. Two additional references were identified from the forward snowballing in iteration 2.

\section{Criteria for saturation}

One criterion for determining when a literature review is complete is whether new meaningful information arises by including more references (vom Brocke et al., 2015). Saturation was considered to be reached if the ratio between the total number of included references to the total number of references examined is very low in iteration 2 compared to that of iteration 1 . In iteration 1 , fifty references were included after screening 813 references. In iteration 2, eight references were included after screening 11,118 references. Because the ratio fell from 6.2 to $0.07 \%$ and no new themes on sensemaking of equations arose in retained publications from iteration 2 , we concluded that the review identified most of the articles related to the field of sensemaking of mathematics in science and therefore was saturated.

\section{Themes developed from the retained publications}

The retained references were read and themes on sensemaking of mathematical equations in science were noted as they arose, and short descriptions were generated. These themes and descriptions were presented to and discussed over several iterations with members of an educational research group resulting in the retention of nine themes. These themes formed the nine categories of the Sci-Math Sensemaking Framework. Distinctions between categories are provided in the results section where descriptions and examples are used to specify the similarities and differences between categories.

\section{Results}

Mathematical equations in science contain conceptual knowledge about mathematics based on the arrangement of the symbols and the operations contained within the equations. These equations also contain connections to a scientific phenomenon. To enable characterization of the sensemaking that is occurring in a science classroom along both of these dimensions, the nine themes identified from the literature review were classified as either 
science sensemaking (referring to making sense of connections to the scientific phenomenon) or mathematics sensemaking (referring to making sense of mathematics). The science sensemaking dimension of the Sci-Math Sensemaking Framework contains four categories while the mathematics sensemaking dimension contains five categories (Table 2).

\section{Categories within the science sensemaking dimension}

There is a rich history of studying how students make sense of science (Berland et al., 2016; diSessa, 1993; Ford, 2012; Kapon, 2016; Odden \& Russ, 2019; Russ, Scherr, Hammer, \& Mikeska, 2008). Science sensemaking is defined as "the process of building an explanation to resolve a perceived gap or conflict in knowledge" (Odden \& Russ, 2019, p. 187). Therefore, science sensemaking of mathematical equations used in science aims at understanding the scientific knowledge represented by the equations. Sensemaking of mathematical equations in science can occur during classroom instruction of equations or during the process of students interpreting or developing or applying equations (Etkina, Warren, \& Gentile, 2006; Hestenes, 2010; Lazenby \& Becker, 2019;
Redish \& Kuo, 2015; Schuchardt \& Schunn, 2016). The four categories describing science sensemaking through mathematical equations in science are Sci-Label, SciDescription, Sci-Pattern, and Sci-Mechanism (Table 2). The four categories are ordered theoretically to represent an increasingly sophisticated understanding of the scientific phenomenon.

\section{Sci-Label sensemaking}

Sci-Label sensemaking refers to connecting variables in mathematical equations with characteristics of objects or processes within the scientific phenomena. These characteristics could refer to quantifiable aspects of specific objects in the phenomenon (e.g., number of sperm types, mass) or they could refer to a quantity that characterizes a process within the phenomenon (e.g., time, temperature, force) (Becker et al., 2017; Becker \& Towns, 2012; Bing \& Redish, 2007; Geyer \& KuskeJanßen, 2019; Hansson, Hansson, Juter, \& Redfors, 2015; Hu \& Rebello, 2013; Izsák, 2004; Kuo et al., 2013; Lehavi et al., 2017; Pietrocola, 2009; Quale, 2011; Redish, 2017; Redish \& Kuo, 2015; Rodriguez et al., 2019; Schuchardt, 2016; Schuchardt \& Schunn, 2016; Svoboda \& Passmore,

Table 2 Categories synthesized from literature to capture the sensemaking opportunities of mathematical equations in science classrooms

\begin{tabular}{|c|c|c|c|}
\hline Dimension & Category & Short definition & Selected references \\
\hline \multirow[t]{4}{*}{$\begin{array}{l}\text { Science } \\
\text { sensemaking }\end{array}$} & Sci-Label & $\begin{array}{l}\text { Connects variables or operators in mathematical equations to } \\
\text { quantifiable characteristics of objects or processes in the scientific } \\
\text { phenomenon, i.e., the definition or scientific meaning of the } \\
\text { variable (e.g., } m=\text { mass) }\end{array}$ & $\begin{array}{l}\text { Hansson et al., 2015; Hestenes, 2010; Izsák, 2004; Kuo } \\
\text { et al., 2013; Quale, 2011; Redish \& Kuo, } 2015\end{array}$ \\
\hline & $\begin{array}{l}\text { Sci- } \\
\text { Description }\end{array}$ & $\begin{array}{l}\text { Uses a mathematical equation to provide a quantifiable measure } \\
\text { of a scientific phenomenon or object within the phenomenon. } \\
\text { (e.g., equations for diversity index, the equation for speed) }\end{array}$ & $\begin{array}{l}\text { Bain, Rodriguez, \& Towns, 2019b; Brahmia et al., } \\
\text { 2016; Lehavi et al., 2017; Lehrer \& Schauble, } 2010\end{array}$ \\
\hline & Sci-Pattern & $\begin{array}{l}\text { Emphasizes the trend or pattern among variables in the } \\
\text { mathematical equation situated within the scientific phenomenon } \\
\text { (e.g., in the equation } F=\text { ma, acceleration is proportional to the } \\
\text { force on an object) }\end{array}$ & $\begin{array}{l}\text { Baxter, Ruzicka, Beghetto, \& Livelybrooks, 2014; } \\
\text { Michelsen, 2015; Redish, 2017; Rodriguez et al., } 2019\end{array}$ \\
\hline & $\begin{array}{l}\text { Sci- } \\
\text { Mechanism }\end{array}$ & $\begin{array}{l}\text { Emphasizes connections to a mechanism that explains how or } \\
\text { why a scientific phenomenon occurs (e.g., for the equation } \vec{a} \\
=\vec{F}_{\text {net }} / m \text {, the net force distributed over mass causes the } \\
\text { acceleration of an object in the same direction) }\end{array}$ & $\begin{array}{l}\text { Etkina et al., 2006; Hestenes, 2010; Redish, 2017; } \\
\text { Schuchardt \& Schunn, } 2016\end{array}$ \\
\hline \multirow[t]{5}{*}{$\begin{array}{l}\text { Mathematics } \\
\text { sensemaking }\end{array}$} & $\begin{array}{l}\text { Math- } \\
\text { Procedure }\end{array}$ & $\begin{array}{l}\text { Emphasizes the predetermined steps or algorithms for problem- } \\
\text { solving }\end{array}$ & $\begin{array}{l}\text { Hiebert \& Lefevre, 1986; Hansson et al., 2015; Peled } \\
\text { \& Segalis, } 2005\end{array}$ \\
\hline & Math-Rule & $\begin{array}{l}\text { Focuses on generalizable statements that guide calculation (e.g., } \\
\text { the probability of two events occurring simultaneously is equal to } \\
\text { the product of the individual probabilities) }\end{array}$ & $\begin{array}{l}\text { Bing \& Redish, 2007; Hansson et al., 2015; Potgieter } \\
\text { \& Blignaut, 2017; Schuchardt \& Schunn, } 2016\end{array}$ \\
\hline & $\begin{array}{l}\text { Math- } \\
\text { Structure }\end{array}$ & $\begin{array}{l}\text { Focuses on the form of the equation, the numbers and } \\
\text { arrangement of symbols and operations (e.g., } \square+\square \text { as two } \\
\text { components added together) }\end{array}$ & $\begin{array}{l}\text { Bain, Rodriguez, Moon, \& Towns, 2019; McNeil \& } \\
\text { Alibali, 2004; Pospiech, 2019; Redish, 2017; Sherin, } \\
2001\end{array}$ \\
\hline & $\begin{array}{l}\text { Math- } \\
\text { Relation }\end{array}$ & $\begin{array}{l}\text { Emphasizes quantitative relationships between variables in the } \\
\text { equations (e.g., } v=9.8 \mathrm{~m} / \mathrm{sec}^{2} * t+v_{0} \text { says that if } v_{0} \text { is } 0, v \text { will be } \\
9.8 \text { times bigger for every unit increase in } t \text { ) }\end{array}$ & $\begin{array}{l}\text { Carlson, Jacobs, Coe, Larsen, \& Hsu, 2002; Lehavi } \\
\text { et al., 2017; Rodriguez, Santos-Diaz, Bain, \& Towns, } \\
\text { 2018; Sherin, } 2001\end{array}$ \\
\hline & $\begin{array}{l}\text { Math- } \\
\text { Concept }\end{array}$ & $\begin{array}{l}\text { Refers to a network of knowledge that enables explanation of the } \\
\text { what, how, and why of a mathematical idea (e.g., conceptually, } \\
\text { probability is the proportion of desired events out of all possible } \\
\text { events) }\end{array}$ & $\begin{array}{l}\text { Even, 1990; Hiebert \& Lefevre, 1986; Peled \& Segalis, } \\
\text { 2005; Rittle-Johnson \& Schneider, } 2015\end{array}$ \\
\hline
\end{tabular}


2013; Tuminaro \& Redish, 2007; Wink \& Ryan, 2019). For example, in the equation $\mathrm{F}_{n e t}=\mathrm{ma}$, the variables $F$, $m$, and $a$ are defined as the net force applied to an object, the mass of the object, and the net acceleration of the object, respectively. It should be noted that operators (e.g., division or addition symbols) could also receive labels. For example, the division symbol in $a=F / m$ could be labeled as "distributed over" or simply as "divided by" (Redish, 2017). However, explicit labeling of operators in a manner parallel to variables was not present as a sensemaking process used by students or instructors in any of the papers reviewed.

The first step in students' interpretation of equations or their application of equations to solve problems is often labeling the variables. For example, when students were asked how they would explain the equation $v=$ $v_{0}+a t$ to their friends, one student answered that "I think the first thing you'd need to go over would be the definitions of each variable and what each one means" (Kuo et al., 2013, p. 46). Labeling variables in the mathematical equation has been identified in multiple studies on students' interpretation of equations when solving quantitative problems in science (Becker \& Towns, 2012; Bing \& Redish, 2007; Hu \& Rebello, 2013; Redish \& Gupta, 2010; Rodriguez et al., 2019; Tuminaro \& Redish, 2007). Literature on students' development of mathematical equations also shows that one of the first steps is selecting and quantifying characteristics of the scientific phenomenon as variables (Izsák, 2004; Quale, 2011; Schuchardt \& Schunn, 2016; Svoboda \& Passmore, 2013).

Similarly, during instruction of mathematical equations in science, the first step is often defining the variables in the equation (Hansson et al., 2015; Lehavi et al., 2017; Schuchardt, 2016; Schuchardt \& Schunn, 2016). In their study on the role of mathematics in physics lessons in upper-secondary school, Hansson et al. (2015) presented a description of a lecture on electric fields. The physics teacher introduced the equation $F=E Q$ with " $F$ is the force that the electron senses in the electric field" before proceeding to manipulate the equation (Hansson et al., 2015, p. 628). It has been proposed that this mapping of variables in the equation to objects in the phenomenon sets the foundation for problem-solving (Kuo et al., 2013; Redish \& Kuo, 2015; Rodriguez et al., 2019; Schuchardt, 2016). Because defining important variables relevant to the scientific phenomena is an essential step during the sensemaking of the mathematical equations, but does not go beyond making label connections, this category is placed on the first level of sensemaking in the Sci-Math Sensemaking Framework.

\section{Sci-Description sensemaking}

The Sci-Description sensemaking category captures the use of mathematics to provide a measure of properties of physical objects, or of scientific phenomena or systems (Bain, Rodriguez, \& Towns, 2019b; Brahmia et al., 2016; Geyer \& Kuske-Janßen, 2019; Lehavi et al., 2017; Lehrer \& Schauble, 2010; Pospiech, 2019; Wink \& Ryan, 2019). For example, density is a measure of the property of a substance. The density equation $\rho=m / V$ is an invented quantifiable characteristic derived from the two direct measures, mass and volume (Pospiech, 2019). This category differs from Sci-Label because in Sci-Label the focus is on establishing only the connection between a variable and the name of a characteristic of a scientific phenomenon, e.g., $\rho$ is density, $m$ is mass, and $V$ is volume, while in Sci-Description the entire equation describes how a measure such as density is calculated. Descriptive equations are found across scientific disciplines. In biology, the Shannon index equation is a description of the biodiversity of a biological system. In chemistry, the equation for the equilibrium constant is a measure of the state of a reaction at equilibrium (Bain, Rodriguez, \& Towns, 2019b). Many statistical equations are descriptions of features of a system, e.g., mean, standard deviation (Lehrer \& Schauble, 2010).

Few studies address Sci-Description sensemaking (Brahmia et al., 2016; Lehavi et al., 2017; Lehrer \& Schauble, 2010). Lehavi et al. (2017) describe a class discussion on the definition of speed, "the change in distance versus time" (p. 99), where the instructor tried to focus students' attention on the definition of speed as a derived measure. However, students had difficulty with the idea that speed is a variable described by the equation while time and distance are direct measurements. Several other studies discussed instances where students derived descriptive equations from data. In biology, Lehrer \& Schauble (2010) provide examples of students inventing mathematical equations to describe characteristics of a population of organisms (e.g., variation, average growth, measure of a healthy aquatic system). In physics, Brahmia et al. (2016) listed several examples of students' inventing equations to describe the features of the motion of cars, such as how fast cars move and how rapidly cars speed up.

\section{Sci-Pattern sensemaking}

The category of Sci-Pattern sensemaking emerged from multiple studies suggesting mathematical equations in science represent patterns in scientific phenomena (Bain, Rodriguez, \& Towns, 2019b; Baxter et al., 2014; Becker et al., 2017; Becker \& Towns, 2012; Etkina et al., 2006; Geyer \& Kuske-Janßen, 2019; Gupta \& Elby, 2011; Hestenes, 2010; Hu \& Rebello, 2013; Karam \& Krey, 2015; Kuo et al., 2013; Michelsen, 2015; Pospiech, 2019; Quale, 2011; Redish, 2017; Rodriguez et al., 2019; Sherin, 2006; Svoboda \& Passmore, 2013). The Sci-Pattern category captures sensemaking of the trend or pattern among 
variables in the mathematical expression, how properties of a system vary with respect to one another. For example, possible sensemaking opportunities for science patterns in the equation $\rho=m / V$ are (1) for the same substance, the larger its volume, the larger its mass or (2) for objects with the same volume, the larger its density, the larger its mass. This type of sensemaking differs from Sci-Description because the emphasis is on understanding the relationships among variables in the equation as opposed to understanding that the equation is providing a descriptive measurement of a specific characteristic of an object or system.

The idea of sensemaking of scientific patterns embodied within a mathematical expression in science is presented in both theoretical and empirical literature about mathematics in science. For example, in chemistry, mathematical equations are often used to describe features of stable and dynamic chemical systems (Bain, Rodriguez, Moon, \& Towns, 2019; Bain, Rodriguez, \& Towns, 2019b; Rodriguez et al., 2019). The Gibbs free energy equation, $\Delta G=\Delta H-T \Delta S$, describes the relationship among change in entropy, change in enthalpy, and the change in free energy in a chemical reaction. One student referred to how the change in enthalpy $(\Delta H)$ and the change in entropy $(\Delta S)$ lead to a negative change in the Gibbs free energy $(\Delta G)$ when explaining the formation of lipid membranes (Redish, 2017). Sci-Pattern sensemaking is a common focus in learning activities designed by teachers to integrate mathematics into science (Baxter et al., 2014; Michelsen, 2015). For example, one group developed a learning module for students to investigate the relationship between the coefficient of friction and braking distance for cars (Michelsen, 2015). In this curriculum, the learning objective was for students to develop an understanding of the pattern that for cars with the same initial speed, the wetter the road, the longer the breaking distance.

\section{Sci-Mechanism sensemaking}

Mathematical equations can be used to describe a causal relationship among objects within the phenomenon (Etkina et al., 2006; Hestenes, 2010; Lazenby, Rupp, Brandriet, Mauger-Sonnek, \& Becker, 2019; Redish, 2017; Redish \& Kuo, 2015; Schuchardt, 2016; Schuchardt \& Schunn, 2016). The causal relationship that can be described by an equation is the scientific mechanism that explains how or why a scientific phenomenon occurs (Machamer, Darden, \& Craver, 2000). A pattern only provides information on which scientific entities are related, but a mechanism shows why the relationship among entities behaves in that way. A single equation can be interpreted or taught as describing a causal mechanism and/or describing a pattern. For example, the equation for Ohm's law $I=U / R$, can be interpreted or taught by an individual using Sci-Mechanism sensemaking as describing the causal mechanism for the current: the current $(I)$ in a conductor is caused by (represented by the equals sign) the voltage difference between two points $(U)$ applied across (represented by the division symbol) the resistance $(R)$ (Sci-Mechanism). Alternatively, individuals engaged in Sci-Pattern sensemaking of this equation would focus on the relationship among current, voltage, and resistance (e.g., as resistance increases, current decreases) without describing the cause for this pattern. Often in scientific research, the pattern in a phenomenon is discovered and studied before the mechanism responsible for the pattern. Therefore, Sci-Mechanism is placed at the fourth level of the Science Sensemaking dimension.

Discussion of Sci-Mechanism sensemaking is not common in the literature (Etkina et al., 2006; Hestenes, 2010; Redish, 2017; Schuchardt, 2016; Schuchardt \& Schunn, 2016). Causal relationships among variables in equations is often not explicit in canonical forms because the form of the equation hides the causal relationship. For example, Newton's second law is often structured as $F_{\text {net }}=\mathrm{ma}$, and interpreted as a pattern, the total force on a system in a specific direction is proportional to the acceleration in that direction. If, however, the equation is structured as $\vec{a}=\vec{F}_{\text {net }} / m$, the arrangement of the variables fosters a mechanistic interpretation, the net force distributed over the mass of an object results in acceleration of the object, while the vector indicates the direction of the net force (Redish, 2017). In biology, one curriculum restructured a mathematical equation used to predict offspring outcomes from an expression of probability rules to "number of different offspring outcomes $=$ (number of egg types) $*$ (number of sperm types)" (Schuchardt \& Schunn, 2016). This restructuring shifts the sensemaking focus to the mechanism for inheritance: any egg type can randomly join with any sperm type to produce offspring. Students who were instructed in this curriculum showed improved quantitative skills and conceptual understanding compared to students who were instructed in the use of mathematical algorithms or rules (Schuchardt \& Schunn, 2016).

\section{Categories within the mathematics sensemaking dimension}

Mathematical equations in science do not just contain scientific meaning, they also contain mathematical meaning that can be accessed independently (Bain, Rodriguez, Moon, \& Towns, 2019; Kuo et al., 2013; Sherin, 2001). Therefore, the Sci-Math Sensemaking Framework includes a separate mathematics sensemaking dimension. Categories of sensemaking of mathematics were derived 
from literature on mathematics education and the use of mathematics in science. Five categories emerged from the literature review that captured opportunities for sensemaking of mathematical knowledge. The definitions of these categories are provided in Table 2, and each category will be illustrated below.

\section{Math-Procedure sensemaking}

The Math-Procedure category captures sensemaking that focuses on the procedural knowledge or algorithms for using mathematical equations to solve problems (Bain, Rodriguez, \& Towns, 2019b; Baroody, Feil, \& Johnson, 2007; Becker et al., 2017; Bing \& Redish, 2007; Case \& Gunstone, 2003; Fan \& Bokhove, 2014; Gupta \& Elby, 2011; Haapasalo \& Kadijevich, 2000; Hiebert \& Lefevre, 1986; Hu \& Rebello, 2013; Jacobs, Franke, Carpenter, Levi, \& Battey, 2007; Karam, 2014; Kuo et al., 2013; Lehavi et al., 2017; Peled \& Segalis, 2005; Pietrocola, 2009; Pospiech, 2019; Radmehr \& Drake, 2019; Redish, 2017; Redish \& Kuo, 2015; Rittle-Johnson \& Schneider, 2015; Schuchardt, 2016; Schuchardt \& Schunn, 2016; Star, 2005; Tsaparlis, 2007; Tuminaro \& Redish, 2007; Uhden, Karam, Pietrocola, \& Pospiech, 2012; Wells, Hestenes, \& Swackhamer, 1995; Wink \& Ryan, 2019). Procedural knowledge was first defined by Hiebert and Lefevre (1986) and has come to mean knowing the sequential steps in solving problems without having conceptual understanding (Baroody et al., 2007; Haapasalo \& Kadijevich, 2000; Jacobs et al., 2007; Star, 2005). Peled and Segalis (2005) presented the subtraction procedure that students can engage in when solving the equation $310-164=$ ? in a mathematics classroom. These steps included (1) borrowing from the tens column, (2) subtracting 4 from the ones column, (3) borrowing from the hundreds column, (4) taking away 6 from the tens column, and (5) taking away 1 from the hundreds column. The focus on procedural knowledge in mathematics classes has been criticized as one reason for students' difficulty in understanding the meaning of equations or adopting efficient problemsolving strategies for new or complex problems (Cañadas, Molina, \& del Río, 2018; Jacobs et al., 2007; Peled \& Segalis, 2005). Similarly, in science classrooms, researchers have found that students tend to rely on algorithms without conceptual understanding of the science in solving problems and teachers tend to focus instruction on using mathematical procedures to do calculation (Bain, Rodriguez, \& Towns, 2019b; Bing \& Redish, 2007; Hansson et al., 2015; Hu \& Rebello, 2013; Kuo et al., 2013; Lehavi et al., 2017; Redish, 2017; Redish \& Gupta, 2010; Redish \& Kuo, 2015; Schuchardt, 2016; Schuchardt \& Schunn, 2016; Tuminaro \& Redish, 2007; Wink \& Ryan, 2019). One description captured a high school physics instructor teaching the equation $F=E Q$. After linking the variables in the equation to science entities, the teacher presented the steps of how to solve the problem mathematically and asked students to work on similar textbook problems (Hansson et al., 2015). The focus on mathematical procedures during instruction might be one reason why many students do not engage in sensemaking of mathematical concepts or make connections to the scientific phenomenon when problem-solving. This category has been placed at the first level in the math sensemaking dimension.

\section{Math-Rule sensemaking}

The Math-Rule sensemaking category identifies sensemaking of generalizable statements derived from fundamental mathematics principles which are used to guide calculation or decision-making (Baroody et al., 2007; Bing \& Redish, 2007; Dixon, Deets, \& Bangert, 2001; Haapasalo \& Kadijevich, 2000; Hansson et al., 2015; Hiebert \& Lefevre, 1986; Moss \& Case, 1999; Njini, 2012; Radmehr \& Drake, 2019). For example, the knowledge of divisibility rules such as a dividend is divisible by 5 if the last digit is 0 or 5 enables quick decision-making of whether a dividend is divisible (Potgieter \& Blignaut, 2017). Rules can be used to guide the step-by-step calculation; however, compared to procedural knowledge, mathematical rules are more generalizable. For example, the rule pertaining to the order of mathematical operations applies to all types of calculation in all problemsolving processes, while the step-by-step procedure for different problems may vary depending on problem type. Because mathematical rules have greater generalizability than mathematical procedures but can still be employed without understanding the other levels, they are placed at the second level of the mathematics sensemaking dimension.

In the literature, references to using mathematical rules to make sense of mathematical equations in science is often found in descriptions of students' problemsolving process rather than during instruction (Bing \& Redish, 2007; Hansson et al., 2015; Hu \& Rebello, 2013; Schuchardt \& Schunn, 2016). When trying to understand the relation between the direction of velocity and the viscous force represented by the equation $F_{\mathrm{v}}=-b v$, students referred to the mathematical rule that "two negatives cancel out" (Bing \& Redish, 2007). Similarly, Hansson et al. (2015) described how one student manipulated the equation $\left(m g h=\frac{m v^{2}}{2}\right)$ by using the rule of division of fractions. In science classrooms, Schuchardt and Schunn (2016) describe an often-used approach to teaching inheritance where the instructor presents the probability rule that "If both events are required then multiply the probability of the two events together" to help students make sense of calculating the probability 
of producing offspring with specific combinations of genes.

\section{Math-Structure sensemaking}

In the Math-Structure sensemaking category, the focus is on understanding the arrangement of variables (symbols) and operations of the mathematical equations (Bain, Rodriguez, \& Towns, 2019a, 2019b; Becker \& Towns, 2012; Bing \& Redish, 2007; Brahmia et al., 2016; Cañadas et al., 2018; Hestenes, 2010; J. Hiebert \& Lefevre, 1986; Hu \& Rebello, 2013; Izsák, 2004; Jacobs et al., 2007; Karam, 2014; Karam \& Krey, 2015; Kirshner, 1989; Kuo et al., 2013; Moss \& Case, 1999; Pospiech, 2019; Redish, 2017; Redish \& Kuo, 2015; Rodriguez et al., 2019; Rodriguez et al., 2018; Schuchardt \& Schunn, 2016; Sherin, 2001). The idea of mathematical structure has often been discussed in science education literature from the perspective of symbolic forms, which was proposed by Sherin (2001) as "the particular arrangement of symbols in an equation [that] expresses a meaning that can be understood" (p. 480). Because interpretation of the mathematical structure depends on knowing the symbolic arrangements in particular contexts, greater sensemaking is required than when applying mathematical rules. Therefore, Math-Structure sensemaking is placed at the third level in the Mathematics sensemaking dimension.

Math-Structure sensemaking emphasizes the number and location of the variables and operations in the equation. Compared to the typical addition structure, $3+4+$ $5+3=$, mathematics students are more likely to offer an incorrect answer when the equation is structured as 3 $+4+5=3+\ldots$ (McNeil \& Alibali, 2004). In the development of mathematical representations of scientific phenomena, knowledge of mathematical structures provides resources for scientists to organize mathematical symbols and operations to represent the target relationship in the phenomenon (Pospiech, 2019; Redish \& Kuo, 2015). Sherin (2001) proposed that students use "symbolic forms" to make sense of physics equations. Equations in the symbolic form of $\square+\square$ have a structure of two components adding together. Sherin (2001) provides an example of how students use their knowledge of the mathematical structure of equations to express an idea from their observations of a physical phenomenon that friction consists of two components.

Students tend to memorize the structure of canonical equations without conceptual understanding of the mathematics which leads to their difficulty in choosing or developing a meaningful equation for the target scientific phenomenon (Bain, Rodriguez, Moon, \& Towns, 2019; Becker \& Towns, 2012; Redish, 2017; Rodriguez et al., 2018; Sherin, 2001). For example, Bain, Rodriguez, Moon, and Towns (2019) show that students tend to conflate the ideas of rate constant and equilibrium constant because of similarities in the structure of the equations. One student expresses the difficulty as "It just seems that everything is the same almost, and it's hard to distinguish each equation and each principle" (Bain, Rodriguez, Moon, \& Towns, 2019, p. 1573). This quote suggests that the student recognizes that the equations look the same (have the same structure) but realizes that they represent different concepts (principles).

\section{Math-Relation sensemaking}

Math-Relation sensemaking refers to understanding the quantitative relationships expressed in the equation (Bain, Rodriguez, \& Towns, 2019a; Baroody et al., 2007; Becker et al., 2017; Becker \& Towns, 2012; Cañadas et al., 2018; Carlson et al., 2002; Dixon et al., 2001; Hestenes, 2010; Izsák, 2004; Izsák \& Jacobson, 2017; Jacobs et al., 2007; Karam, 2014; Kuo et al., 2013; Lazenby \& Becker, 2019; Lehavi et al., 2017; Levy \& Wilensky, 2009; Moss \& Case, 1999; Pietrocola, 2009; Pospiech, 2019; Redish, 2017; Redish \& Kuo, 2015; Rodriguez et al., 2018; Rodriguez et al., 2019; Schuchardt, 2016; Sherin, 2001; Smidt \& Weiser, 1995; Thompson \& Carlson, 2017; Tuminaro \& Redish, 2007; Uhden et al., 2012; Von Korff \& Sanjay Rebello, 2014; Wink \& Ryan, 2019). Carlson et al. (2002) defined covariational reasoning as attending to the way in which two variables change with respect to one another. For example, in the equation $y=$ $2 x$, the math-relation embedded in the equation is that $y$ increases 2-fold for every unit increase in $x$. An understanding of quantitative relationships is often built on an understanding of the mathematical structure of the equation (Bassok, Chase, \& Martin, 1998). However, the mathematical structure is often not referred to during sensemaking of quantitative relationships, perhaps because the knowledge of mathematical structure is intuitive and not explicitly available to students. Because Math-Relation sensemaking of an equation is built on understanding the mathematical structure, MathRelation is placed on the fourth level in the mathematics sensemaking dimension.

Math-Relation sensemaking (coordination of relationship between quantities) has been conflated in the literature with Sci-Pattern sensemaking (coordination of the relationship between properties of a scientific phenomenon) (e.g., Carlson et al., 2002). We have distinguished them in this framework because as in the example of the equation for a line, $y=2 x$, quantitative coordination can occur separately from any knowledge of connection to real-world measures. Moreover, when discussing sensemaking of mathematical equations in science classrooms, it has been observed that students tend to limit their sensemaking to the Math-Relation sensemaking space (Becker \& Towns, 2012; Izsák, 2004; 
Lehavi et al., 2017; Svoboda \& Passmore, 2013; Wink \& Ryan, 2019). In Izsák's study, two students developed a mathematical equation to represent the relationship of turns of a crank handle to the distance a weight is moved, and they discuss the phenomenon entirely in terms of quantitative relationships "Zero inches moves 4 point 5 inches per crank. And the weight starting at 14 inches only moves 3 inches." (Izsák, 2004, p. 494) There is no discussion of the physics of the phenomenon. In another study (Lehavi et al., 2017), the teacher expressed concern that "for students who hold the mathematical conceptualization, time, speed and distance are merely three quantities related by an equation" even when the teacher tried to use a teaching strategy to move students into physical understanding of the equation. In this case, students were limiting their sensemaking to the quantitative relationships between time, speed, and distance. They were not connecting to the Sci-Pattern sensemaking that speed, time, and distance are physical properties of a scientific phenomenon that have a logical relationship to one another: if speed increases, the distance traveled in a specific time period will also increase.

\section{Math-Concept sensemaking}

Math-Concept sensemaking focuses on a network of knowledge that enables explanation of the what, how, and why of a mathematical idea, referred to as conceptual knowledge (Baroody et al., 2007; Even, 1990; Fan \& Bokhove, 2014; Fuson et al., 1997; Haapasalo \& Kadijevich, 2000; Hiebert \& Lefevre, 1986; Hu \& Rebello, 2013; Jacobs et al., 2007; Moss \& Case, 1999; Peled \& Segalis, 2005; Radmehr \& Drake, 2019; Star, 2005; Thompson \& Carlson, 2017). For example, a conceptual understanding of probability for two independent events $A$ and $B$ cooccurring includes understanding what probability means, why the individual probabilities for the two events are multiplied, and when to perform this calculation and why. Sensemaking of mathematical concepts is the prerequisite for reasoning and justification in mathematics problemsolving (Peled \& Segalis, 2005).

Students struggle with conceptual understanding of various mathematical ideas in mathematics classrooms (Even, 1990; Jacobs et al., 2007; Moss \& Case, 1999). Incorrect or incomplete understanding of the concepts can lead to adoption of incorrect procedures and rules, or difficulty in solving novel problems (Jacobs et al., 2007). For example, students sometimes provide 93 as the answer for $57+36=?+34$, instead of 59 . This error indicates that they are treating the equals sign as a signal to carry out the calculation that precedes it instead of treating it as an indicator of a relationship between the two sides of the equation (Jacobs et al., 2007). Concept-based reasoning in mathematics can lead to more efficient problem-solving. Peled and Segalis (2005) investigated students' problem-solving with subtraction. When students were asked to solve a word problem for the time difference between "one week, 5 days, and 18 hours" and " 2 weeks, 3 days and 4 hours," students who applied a more conceptual strategy were more successful than those who applied a rules-based approach that dictated that all units of time needed to be converted to the same unit. The difficulty that students have with conceptual understanding in mathematics has been attributed to a focus in instruction on procedures over concepts (Hill et al., 2005).

Math-Concept sensemaking in science classrooms is relatively underexplored. One biology curriculum developed by Schuchardt and Schunn (2016) seeks to have students understand the concept of probability in the context of inheritance as the number of desired events out of all possible events. Students who participated in this curriculum showed improved ability to solve novel and complex probability problems situated in inheritance compared to students who were not exposed to this curriculum. Reflecting the mathematics education literature, Math-Concept is placed at the highest level of the mathematics sensemaking dimension.

\section{Discussion}

The Sci-math sensemaking framework is informed by research across multiple fields

The categories of sensemaking identified in this paper are drawn from literature from several fields including studies of mathematics in science education, and mathematics education. Research from physics, chemistry, and biology was synthesized to identify the four categories in the science sensemaking dimension of the SciMath Sensemaking Framework. Therefore, the types of science sensemaking that have been identified are expected to apply across different disciplines. Additionally, evidence from both mathematics education and science education was used to generate each category in the mathematics sensemaking dimension of the framework. These categories represent a synthesis of ideas from both fields. Therefore, the Sci-Math Sensemaking Framework is expected to provide a common structure for education studies on mathematics in science contexts. The availability of a common structure will enable descriptions of instruction in sensemaking and students' sensemaking of equations during problem-solving to be compared across disciplines. Comparative studies will permit the abstraction of common principles that aid in sensemaking as well as the development of testable models of how students engage in sensemaking and how sensemaking of equations affects students' problem-solving.

\section{Sensemaking opportunities on the science dimension}

Categorization of the science sensemaking opportunities when working with mathematical equations in science 
offers a framework for exploring the different types of sensemaking that occurs in science classrooms. The four sensemaking categories on the science dimension emerged from literature on the process of mathematical modeling in science (Etkina et al., 2006; Hestenes, 2010; Izsák, 2004; Lazenby \& Becker, 2019; Lehrer \& Schauble, 2010; Levy \& Wilensky, 2009; Michelsen, 2015; Redish, 2005, 2017; Redish \& Gupta, 2009; Redish \& Kuo, 2015; Uhden et al., 2012), descriptions of students' sensemaking of mathematics in science during problem-solving (Hu et al., 2013; Rodriguez et al., 2018; Sherin, 2001), and descriptions of instructional approaches to teaching mathematics in science (Lehrer \& Schauble, 2010; Michelsen, 2015; Schuchardt \& Schunn, 2016).

\section{Sensemaking opportunities on the mathematics dimension}

The categories identified in the mathematics sensemaking dimension of the Sci-Math Sensemaking Framework provide a nuanced description of the multiple types of mathematics sensemaking that can occur when working with mathematical equations in science. The teaching and learning of mathematical procedures, rules, structure, relation, and concepts have been widely discussed in mathematics education studies (Baroody, 2003; Cañadas et al., 2018; Hiebert \& Lefevre, 1986; Moss \& Case, 1999; Peled \& Segalis, 2005; Star, 2005). The use of mathematics in science offers the opportunity for students to practice mathematics as mathematicians, thus developing their mathematical thinking (Schoenfeld, 1992). In science, development of canonical mathematical expressions in science involves selection of a mathematical structure, including the specific variables and their arrangement, that best represents a specific scientific idea (Borromeo Ferri, 2006; Dukerich, 2015; Diaz Eaton et al., 2019; Gouvea \& Passmore, 2017; Halloun, 2007; Hestenes, 2010). However, during instruction of mathematical equations in science, the rich knowledge in mathematics is often neglected (Hansson et al., 2015; Lazenby \& Becker, 2019; Redish \& Kuo, 2015; Svoboda \& Passmore, 2013). By including a separate mathematics sensemaking dimension, the SciMath Sensemaking Framework emphasizes the importance of mathematics sensemaking as a means for students to grapple with the represented science concepts (Bain, Rodriguez, Moon, \& Towns, 2019; Brahmia et al., 2016; Sherin, 2001).

\section{Relationship among different categories of sensemaking}

The categories within the dimensions of the Sci-Math Sensemaking Framework have been organized to represent increasingly sophisticated levels of sensemaking from Sci-Label to Sci-Mechanism in the science sensemaking dimension and from Math-Procedure to MathConcept in the mathematics sensemaking dimension. These levels have been theorized based on the referenced literature and on logic. For example, in the literature of science education, mechanistic reasoning is thought to reflect a deeper understanding of the scientific phenomenon than sensemaking of the labels of the entities or of the pattern in the phenomenon. (Machamer et al., 2000; Illari \& Williamson, 2012; Russ et al., 2008). Logically, understanding Sci-Mechanism requires identifying associations between variables in the mathematical equation and properties of the scientific phenomenon. However, the placement of some of these levels (e.g., SciDescription below Sci-Pattern) needs to be assessed by additional research.

During the interpretation or instruction of one equation, multiple types of sensemaking may occur simultaneously. With reference to the density equation, SciDescription sensemaking can only occur after the referents of the variables have been understood (Sci-Label sensemaking), and Sci-Description sensemaking can occur together with understanding the patterns represented in the equation (Sci-Pattern). Similarly, in the mathematics dimension, Math-Concept is the most advanced type of sensemaking, but Math-Concept sensemaking may occur in conjunction with application of procedures and rules and sensemaking of mathematical structures.

In science classrooms, little priority is placed on SciMechanism or Math-Concept sensemaking of mathematical equations (Bing \& Redish, 2009; Schuchardt \& Schunn, 2016; Stamovlasis et al., 2005). Sensemaking at these higher levels has shown promise with elevating students' understanding of science concepts and their ability to solve quantitative problems (Mestre, Docktor, Strand, \& Ross, 2011; Schuchardt \& Schunn, 2016; Taasoobshirazi \& Glynn, 2009). However, this does not mean that instruction of mathematical equations needs to always occur at these higher levels. For example, if the goal is to rapidly develop students' ability to quickly solve problems of the same type, then Sci-Label and Math-Procedure may be most efficient. Additionally, some equations can only enable a Sci-Description or Sci-Pattern sensemaking (e.g., density equation or diversity index).

\section{Sci-math Sensemaking framework to identify opportunities for blended sensemaking}

Specifying the sensemaking occurring in each of the two dimensions of the Sci-Math Sensemaking Framework will permit identification and description of opportunities provided for blended sensemaking (Fauconnier \& Turner, 1998). For example, students who rely on algorithms without connection to the scientific knowledge embodied in the equations (Becker \& Towns, 2012; Bing \& Redish, 2009; Case \& Gunstone, 2003; Kuo et al., 2013; Stewart, 1983) are using Sci-Label sensemaking to 
identify the variables combined with Math-Procedure to solve the problem following a prescribed step-by-step process. These two types of sensemaking provide little opportunity for blended sensemaking, and students using these two types of sensemaking have difficulty applying the mathematical equation to different contexts (Redish, 2017; Stewart, 1983; Taasoobshirazi \& Glynn, 2009). On the other hand, when students combine sensemaking of mathematical structures of an equation with sensemaking of mechanisms responsible for the scientific phenomenon, they are blending two types of sensemaking (Math-Structure and Sci-Mechanism) (Sherin, 2001). Students may start sensemaking of mathematical equations from either the mathematics sensemaking dimension or the science sensemaking dimension. In chemistry, accessing sensemaking of an equation from either dimension could result in students moving to the other dimension for a richer understanding of the equation (Bain et al., 2018). Instruction that provides opportunities for blended sensemaking has been shown to improve students' understanding of the scientific phenomenon and their ability to solve complex and novel quantitative problems (Schuchardt \& Schunn, 2016). Additionally, those with more experience in a field are more likely to apply blended sensemaking to and be more successful at solving quantitative problems, than those with less experience (Redish, 2017).

\section{Relationship between sensemaking opportunities and pedagogical strategies}

The types of sensemaking opportunities of mathematical equations in science are often related to the pedagogical strategies that are used. Evidence from innovative instructional approaches synthesized in this review shows that instruction which has students develop mathematical equations to model scientific phenomena can create opportunities for students to engage in higher levels of sensemaking, including SciDescription (Lehrer \& Schauble, 2010), Sci-Pattern (Baxter et al., 2014), Sci-Mechanism (Schuchardt \& Schunn, 2016), Math-Structure (Izsák, 2004), and Math-Concept (Schuchardt \& Schunn, 2016). However, this relationship is not absolute. Sensemaking can occur in classes taught by different methods. Students can spontaneously engage in Sci-Mechanism and Math-Structure sensemaking after having equations provided to them during instruction (Mestre et al., 2011; Redish, 2017; Stewart, 1983; Taasoobshirazi \& Glynn, 2009). By separating sensemaking from pedagogical strategies, it is possible to investigate whether different teaching methods can promote or limit the type of sensemaking opportunities that occur during students' quantitative problem-solving.

\section{Limitations}

The categories of sensemaking of equations in science that are presented in the Sci-Math Sensemaking Framework are drawn from published literature. Moreover, the scientific disciplines that were included were only biology, physics, and chemistry, excluding disciplines such as geology. It is possible that other sensemaking opportunities will be discovered during analysis of instruction in different contexts or in investigation of scientists' use of mathematics in their work. The framework is intended to be modifiable to allow addition of new categories.

\section{Conclusions}

This Sci-Math Sensemaking Framework is generated from a systematic literature review that combines theoretical and empirical evidence on the teaching and learning of equations in mathematics and science. The categories developed in this study capture sensemaking opportunities of equations in science that has rarely been studied. This framework can provide a consistent way for researchers to compare sensemaking of mathematical equations in science across studies. The framework is intended to be used by researchers to examine students' interpretation and application of mathematical equations as well as the sensemaking opportunities created during class by instructors. This framework may also be used by instructors to reflect on their own teaching, to examine whether the sensemaking opportunities provided in class align with their learning objectives.

\section{Supplementary Information}

The online version contains supplementary material available at https://doi. org/10.1186/s40594-020-00264-x.

Additional file 1: Table S1

\section{Abbreviations}

MISCOP: Mathematics Integrated into Science: Classroom Observation ProtocolSTEMScience, Technology, Engineering and Mathematics

\section{Acknowledgements}

We would like to thank the Schuchardt/Warfa research group members for providing constructive feedback on the work. We also appreciated Professor Gillian Roehrig's feedback on this manuscript.

\section{Authors' contributions}

FZ performed the literature review, developed the themes of the presented framework, and was the primary writer of the manuscript. AS advised on the strategy of the literature review, co-developed the themes and descriptions of the presented framework, and co-wrote the manuscript. The authors read and approved the final manuscript.

\section{Funding}

This study was funded by start-up funds awarded to the AS by the University of Minnesota. The funding body had no role in the design of the study and collection, analysis, and interpretation of data and in writing the manuscript should be declared.

Availability of data and materials Not applicable.

Competing interests

The authors declare that they have no competing interests. 


\section{Author details}

'School of Teacher Education, Nanjing Normal University, No.1 Wenyuan Road, Qixia District, Nanjing, P.R. China 210046. ${ }^{2}$ Department of Biology Teaching and Learning, College of Biological Sciences, University of Minnesota-Twin Cities, 5-210H Moos Tower, 515 Delaware Street, SE, Minneapolis, MN 55455, USA.

Received: 3 June 2020 Accepted: 13 December 2020

\section{Published online: 11 February 2021}

\section{References}

Baig, S., \& Halai, A. (2006). Learning Mathematical Rules with Reasoning. EURASIA Journal of Mathematics, Science and Technology Education, 2(2).

Bain, K., Rodriguez, J.-M. G., Moon, A., \& Towns, M. H. (2018). The characterization of cognitive processes involved in chemical kinetics using a blended processing framework. Chemistry Education Research and Practice, 19(2), 617-628. https:// doi.org/10.1039/C7RP00230K.

Bain, K., Rodriguez, J.-M. G., Moon, A., \& Towns, M. H. (2019). Mathematics in chemical kinetics: Which is the cart and which is the horse? In M. H. Towns, K. Bain, \& J.-M. G. Rodriguez (Eds.), It's Just Math: Research on Students' Understanding of Chemistry and Mathematics (Vol. 1316), (pp. 25-46). https:// doi.org/10.1021/bk-2019-1316.ch003.

Bain, K., Rodriguez, J.-M. G., \& Towns, M. H. (2019a). Chemistry and mathematics: Research and frameworks to explore student reasoning. Journal of Chemical Education, 96(10), 2086-2096. https://doi.org/10.1021/acs.jchemed.9b00523.

Bain, K., Rodriguez, J.-M. G., \& Towns, M. H. (2019b). Investigating student understanding of rate constants: When is a constant "constant"? Journal of Chemical Education, 96(8), 1571-1577. https://doi.org/10.1021/acs.jchemed. $9 \mathrm{~b} 00005$

Baroody, A. J. (2003). The development of adaptive expertise and flexibility: The integration of conceptual and procedural knowledge. In A. J. Baroody, \& A. Dowker (Eds.), The development of arithmetic concepts and skills: Constructing adaptive expertise, (pp. 1-33). Mahwah: Lawrence Erlbaum Associates, Inc..

Baroody, A. J., Feil, Y., \& Johnson, A. R. (2007). An alternative reconceptualization of procedural and conceptual knowledge. Journal for Research in Mathematics Education, 38(2), 115-131. https://doi.org/10.2307/30034952.

Bassok, M., Chase, V. M., \& Martin, S. A. (1998). Adding apples and oranges: Alignment of semantic and formal knowledge. Cognitive Psychology, 35(2), 99-134. https://doi.org/10.1006/cogp.1998.0675.

Baxter, J. A., Ruzicka, A., Beghetto, R. A., \& Livelybrooks, D. (2014). Professional development strategically connecting mathematics and science: The impact on teachers' confidence and practice. School Science and Mathematics, 114(3), 102-113. https://doi.org/10.1111/ssm.12060.

Becker, N., \& Towns, M. (2012). Students' understanding of mathematical expressions in physical chemistry contexts: An analysis using Sherin's symbolic forms. Chemistry Education Research and Practice, 13(3), 209-220. https://doi.org/10.1039/C2RP00003B.

Becker, N. M., Rupp, C. A., \& Brandriet, A. (2017). Engaging students in analyzing and interpreting data to construct mathematical models: An analysis of students' reasoning in a method of initial rates task. Chemistry Education Research and Practice, 18(4), 798-810. https://doi.org/10.1039/c6rp00205f.

Berland, L. K., Schwarz, C. V., Krist, C., Kenyon, L., Lo, A. S., \& Reiser, B. J. (2016). Epistemologies in practice: Making scientific practices meaningful for students. Journal of Research in Science Teaching, 53(7), 1082-1112. https:// doi.org/10.1002/tea.21257.

Bialek, W., \& Botstein, D. (2004). Introductory science and mathematics education for 21st-century biologists. Science, 303(5659), 788-790. https://doi.org/10. 1126/science.1095480.

Bing, T. J., \& Redish, E. F. (2007). The cognitive blending of mathematics and physics knowledge. AlP Conference Proceedings, 883, 26-29. https://doi.org/10. 1063/1.2508683.

Bing, T. J., \& Redish, E. F. (2008). Symbolic manipulators affect mathematical mindsets. American Journal of Physics, 76(4), 418-424. https://doi.org/10.1119/ 1.2835053.

Bing, T. J., \& Redish, E. F. (2009). Analyzing problem solving using math in physics: Epistemological framing via warrants. Physical Review Special Topics - Physics Education Research, 5(2), 020108. https://doi.org/10.1103/PhysRevSTPER.5. 020108.

Bing, T. J., \& Redish, E. F. (2012). Epistemic complexity and the journeyman-expert transition. Physical Review Special Topics - Physics Education Research, 8(1), 010105.
Blum, W., \& Borromeo, R. (2009). Mathematical modelling: Can it be taught and learnt? Journal of Mathematical Modelling and Application, 1(1), 45-58.

Boston, M. (2012). Assessing instructional quality in mathematics. The Elementary School Journal, 113(1), 76-104. https://doi.org/10.1086/666387.

Brahmia, S. W., Boudreaux, A., \& Kanim, S. E. (2016). Developing mathematization with physics invention tasks. ArXiv PreprintFebruary, arXiv, 1602.02033.

Brush, S. G. (2015). Mathematics as an instigator of scientific revolutions. Science \& Education, 24(5-6), 495-513. https://doi.org/10.1007/s11191-015-9762-x.

Cañadas, M. C., Molina, M., \& del Río, A. (2018). Meanings given to algebraic symbolism in problem-posing. Educational Studies in Mathematics, 98(1), 19-37. https://doi.org/10.1007/s10649-017-9797-9.

Carlson, M., Jacobs, S., Coe, E., Larsen, S., \& Hsu, E. (2002). Applying covariational reasoning while modeling dynamic events: A framework and a study. Journal for Research in Mathematics Education, 33(5), 352. https://doi.org/10.2307/4149958.

Case, J. M., \& Gunstone, R. F. (2003). Approaches to learning in a second year chemical engineering course. International Journal of Science Education, 25(7), 801-819. https://doi.org/10.1080/09500690305033.

Chen, Y., Irving, P. W., \& Sayre, E. C. (2013). Epistemic game for answer making in learning about hydrostatics. Physical Review Special Topics - Physics Education Research, 9(1), 010108.

de Ataíde, A. R. P., \& Greca, I. M. (2013). Epistemic views of the relationship between physics and mathematics: Its influence on the approach of undergraduate students to problem solving. Science \& Education, 22(6), 1405-1421. https://doi. org/10.1007/s11191-012-9492-2.

De Berg, K. C. (1992). Mathematics in science: The role of the history of science in communicating the significance of mathematical formalism in science. Science \& Education, 1, 77-87.

Diaz Eaton, C., Highlander, H. C., Dahlquist, K. D., Ledder, G., LaMar, M. D., \& Schugart, R. C. (2019). A "rule-of-five" framework for models and modeling to unify mathematicians and biologists and improve student learning. PRIMUS, 29(8), 799-829. https://doi.org/10.1080/10511970.2018.1489318.

diSessa, A. A. (1993). Toward an epistemology of physics. Cognition and Instruction, 10(2-3), 105-225. https://doi.org/10.1080/07370008.1985.9649008.

Dixon, J. A., Deets, J. K., \& Bangert, A. (2001). The representations of the arithmetic operations include functional relationships. Memory and Cognition, 29(3), 462-477. https://doi.org/10.3758/BF03196397.

Dreyfus, B. W., Elby, A., Gupta, A., \& Sohr, E. R. (2017). Mathematical sense-making in quantum mechanics: An initial peek. Physical Review Physics Education Research, 13(2), 020141.

Dukerich, L. (2015). Applying modeling instruction to high school chemistry to improve students' conceptual understanding. Journal of Chemical Education, 92(8), 1315-1319. https://doi.org/10.1021/ed500909w.

Eichenlaub, M., \& Redish, E. F. (2019). Blending physical knowledge with mathematical form in physics problem solving. In G. Pospiech, M. Michelini, \& B.-S. Eylon (Eds.), Mathematics in physics education, (pp. 127-151).

Etkina, E., Warren, A., \& Gentile, M. (2006). The role of models in physics instruction. The Physics Teacher, 44(1), 34-39. https://doi.org/10.1119/1.2150757.

Even, R. (1990). Subject matter knowledge for teaching and the case of functions. Educational Studies in Mathematics, 21(6), 521-544.

Fan, L., \& Bokhove, C. (2014). Rethinking the role of algorithms in school mathematics: A conceptual model with focus on cognitive development ZDM - International Journal on Mathematics Education, 46(3), 481-492. https:// doi.org/10.1007/s11858-014-0590-2.

Fauconnier, G., \& Turner, M. (1998). Conceptual integration networks. Cognitive Science, 22(2), 133-187. https://doi.org/10.1207/s15516709cog2202_1.

Ferri, R. B. (2006). Theoretical and empirical differentiations of phases in the modelling process. ZDM - International Journal on Mathematics Education, 38(2), 86-95. https://doi.org/10.1007/BF02655883.

Flores-García, S., Terrazas, S. M., González-Quezada, M. D., Pierce, J. L. C., \& Soto, S. E. (2008). Student use of vectors in the context of acceleration. Revista Mexicana de Fisica E, 54(2), 133-140.

Ford, M. J. (2012). A dialogic account of sense-making in scientific argumentation and reasoning. Cognition and Instruction, 30(3), 207-245. https://doi.org/10. 1080/07370008.2012.689383.

Fuson, K. C., Wearne, D., Hiebert, J. C., Murray, H. G., Human, P. G., Olivier, A. I., Carpenter, T.P., \& Fennema, E. (1997). Children's conceptual structures for multidigit numbers and methods of multidigit addition and subtraction. Journal for Research in Mathematics Education, 130-162.

Geyer, M.-A., \& Kuske-Janßen, W. (2019). Mathematical representations in physics lessons. In B. S. Pospiech, G. Michelini, \& M. Eylon (Eds.), Mathematics in physics education, (pp. 75-102). https://doi.org/10.1007/978-3-030-04627-9_4. 
Ghosh, A. (2009). The little known story of $\mathrm{F}=\mathrm{ma}$ and beyond. Resonance, 14(12), 1153-1165. https://doi.org/10.1007/s12045-009-0110-9.

Gierer, R. N. (2004). How models are used to represent reality. Philosophy of Science, 71(5), 742-752. https://doi.org/10.1086/425063.

Gingras, Y. (2001). What did mathematics do to physics? History of Science, 39(4), 383-416. https://doi.org/10.1177/007327530103900401.

Gouvea, J., \& Passmore, C. (2017). Models of' versus 'models for. Science \& Education, 26(1-2), 49-63. https://doi.org/10.1007/s11191-017-9884-4.

Greca, I. M., \& Moreira, M. A. (2002). Mental, physical, and mathematical models in the teaching and learning of physics. Science Education, 86(1), 106-121. https://doi.org/10.1002/sce.10013.

Gupta, A., \& Elby, A. (2011). Beyond epistemological deficits: Dynamic explanations of engineering students' difficulties with mathematical sensemaking. International Journal of Science Education, 33(18), 2463-2488. https:// doi.org/10.1080/09500693.2010.551551.

Haapasalo, L., \& Kadijevich, D. (2000). Two types of mathematical knowledge and their relation. Journal für Mathematik-Didaktik, 21(2), 139-157. https://doi.org/ 10.1007/BF03338914.

Halloun, I. A. (2007). Mediated modeling in science education. Science \& Education, 16(7-8), 653-697. https://doi.org/10.1007/s11191-006-9004-3.

Hammer, D. (2000). Student resources for learning introductory physics. American Journal of Physics, 68(S1), S52-S59.

Hammer, D., Elby, A., Scherr, R. E., \& Redish, E. F. (2005). Resources, framing, and transfer. In Transfer of learning from a modern multidisciplinary perspective, (p. 89).

Hansson, L., Hansson, Ö., Juter, K., \& Redfors, A. (2015). Reality-theoretical models-mathematics: A ternary perspective on physics lessons in uppersecondary school. Science \& Education, 24(5-6), 615-644. https://doi.org/10. 1007/s11191-015-9750-1.

Heisterkamp, K., \& Talanquer, V. (2015). Interpreting data: The hybrid mind. Journal of Chemical Education, 92(12), 1988-1995. https://doi.org/10.1021/acs. jchemed.5b00589.

Hestenes, D. (2010). Modeling theory for math and science education. In R. A. Lesh, P. L. Galbraith, C. R. Haines, \& Hurford (Eds.), Modeling students' mathematical modeling competencies, (pp. 13-41). https://doi.org/10.1007/ 978-1-4419-0561-1_3.

Hiebert, J., \& Lefevre, P. (1986). Conceptual and procedural knowledge in mathematics: An introductory analysis. In J. Hiebert (Ed.), Conceptual and procedural knowledge: The case of mathematics (pp. 1-27). Hillsdale: Lawrence Erlbaum Associates Inc.

Hill, H. C., Rowan, B., \& Ball, D. L. (2005). Effects of teachers' mathematical knowledge for teaching on student achievement. American Educational Research Journal, 42(2), 371-406. https://doi.org/10.3102/00028312042002371.

Hu, D., \& Rebello, N. S. (2013). Using conceptual blending to describe how students use mathematical integrals in physics. Physical Review Special Topics - Physics Education Research, 9(2), 1-15. https:/doi.org/10.1103/PhysRevSTPER.9.020118.

Hutchison, P., \& Hammer, D. (2009). Attending to student epistemological framing in a science classroom. Science Education, 94(3), 506-524. https://doi. org/10.1002/sce.20373.

Illari, P. M., \& Williamson, J. (2012). What is a mechanism? Thinking about mechanisms across the sciences. European Journal for Philosophy of Science, 2(1), 119-135.

Izsák, A. (2004). Students' coordination of knowledge when learning to model physical situations. Cognition and Instruction, 22(1), 81-128. https://doi.org/10. 1207/s1532690Xci2201_4.

Izsák, A., \& Jacobson, E. (2017). Preservice teachers' reasoning about relationships that are and are not proportional: A knowledge-in-pieces account. Journal for Research in Mathematics Education, 48(3), 300-339.

Jacobs, V. R., Franke, M. L., Carpenter, T. P., Levi, L., \& Battey, D. (2007). Professional development focused on children's algebraic reasoning in elementary school. Journal for Research in Mathematics Education, 38(3), 258-288.

Judson, E. (2013). Development of an instrument to assess and deliberate on the integration of mathematics into student-centered science learning. School Science and Mathematics, 113(2), 56-68. https://doi.org/10.1111/ssm.12004.

Kang, H., Windschitl, M., Stroupe, D., \& Thompson, J. (2016). Designing, launching, and implementing high quality learning opportunities for students that advance scientific thinking. Journal of Research in Science Teaching, 53(9), 1316-1340. https://doi.org/10.1002/tea.21329.

Kapon, S. (2016). Unpacking sensemaking. Science Education, 101(1), 165-198. https://doi.org/10.1002/sce.21248.

Karam, R. (2014). Framing the structural role of mathematics in physics lectures: A case study on electromagnetism. Physical Review Special Topics - Physics Education Research, 10(1), 010119. https://doi.org/10.1103/PhysRevSTPER.10.010119.
Karam, R., \& Krey, O. (2015). Quod erat demonstrandum: Understanding and explaining equations in physics teacher education. Science \& Education, 24(5-6), 661-698. https://doi.org/10.1007/s11191-015-9743-0.

Kirshner, D. (1989). The visual syntax of algebra. Journal for Research in Mathematics Education, 20(3), 274-287.

Koretsky, M., Keeler, J., Ivanovitch, J., \& Cao, Y. (2018). The role of pedagogical tools in active learning: A case for sense-making. International journal of STEM education, 5(1), 18.

Kranzfelder, P., Bankers-Fulbright, J. L., García-Ojeda, M. E., Melloy, M., Mohammed, S., \& Warfa, A.-R. M. (2019). The classroom discourse observation protocol (CDOP): A quantitative method for characterizing teacher discourse moves in undergraduate STEM learning environments. PLOS One, 14(7), e0219019. https://doi.org/10.1371/journal.pone.0219019.

Kuo, E., Hull, M. M., Gupta, A., \& Elby, A. (2013). How students blend conceptual and formal mathematical reasoning in solving physics problems. Science Education, 97(1), 32-57. https://doi.org/10.1002/sce.21043.

Lazenby, K., \& Becker, N. M. (2019). A modeling perspective on supporting students' reasoning with mathematics in chemistry. In M. H. Towns, K. Bain, \& J.-M. G. Rodriguez (Eds.), It's Just Math: Research on Students' Understanding of Chemistry and Mathematics (Vol. 1316), (pp. 9-24). https://doi.org/10.1021/bk2019-1316.ch002

Lazenby, K., Rupp, C. A., Brandriet, A., Mauger-Sonnek, K., \& Becker, N. M. (2019). Undergraduate chemistry students' conceptualization of models in general chemistry. Journal of Chemical Education, 96(3), 455-468. https://doi.org/10. 1021/acs.jchemed.8b00813.

Learning Mathematics for Teaching Project (2011). Measuring the mathematical quality of instruction. Journal of Mathematics Teacher Education, 14, 25-47. https://doi.org/10.1007/s10857-010-9140-1.

Lehavi, Y., Bagno, E., Eylon, B.-S., Mualem, R., Pospiech, G., Böhm, U., ... Karam, R. (2017). Classroom evidence of teachers' PCK of the interplay of physics and mathematics. In T. Greczyło, \& E. Dębowska (Eds.), Key competences in physics teaching and learning, (pp. 95-104). https://doi.org/10.1007/978-3-319-44887-9.

Lehrer, R., \& Schauble, L. (2010). What kind of explanation is a model? In M. K. Stein, \& L. Kucan (Eds.), Instructional explanations in the disciplines, (pp. 9-22). https://doi.org/10.1007/978-1-4419-0594-9_2.

Levy, S. T., \& Wilensky, U. (2009). Crossing levels and representations: The connected chemistry (CC1) curriculum. Journal of Science Education and Technology, 18(3), 224-242. https://doi.org/10.1007/s10956-009-9152-8.

Li, Y., \& Schoenfeld, A. H. (2019). Problematizing teaching and learning mathematics as "given" in STEM education. International Journal of STEM Education, 6(1). https://doi.org/10.1186/s40594-019-0197-9.

Litke, E. (2020). The nature and quality of algebra instruction: Using a contentfocused observation tool as a lens for understanding and improving instructional practice. Cognition and Instruction, 38(1), 57-86.

Lo, M. L., Marton, F., Pang, M. F., \& Pong, W. Y. (2004). Toward a pedagogy of learning. In F. Marton, \& A. B. M. Tsui (Eds.), Classroom discourse and the space of learning, (pp. 189-226). https://doi.org/10.4324/9781410609762.

Lythcott, J. (1990). Problem solving and requisite knowledge of chemistry. Journal of Chemical Education, 67(3), 248-252. https://doi.org/10.1021/ed067p248.

Machamer, P., Darden, L., \& Craver, C. F. (2000). Thinking about mechanisms. Philosophy of Science, 67(1), 1-25 Retrieved from http://www.jstor.org/stable/188611.

Martin, W. G., \& Kasmer, L. (2009). Reasoning and sense making. Teaching Children Mathematics, 16(5), 284-291.

Marton, F., Runesson, U., \& Tsui, A. B. M. (2004). The space of learning. In F. Marton, \& A. B. M. Tsui (Eds.), Classroom discourse and the space of learning, (pp. 3-42). https://doi.org/10.4324/9781410609762.

McNeil, N. M., \& Alibali, M. W. (2004). You'll see what you mean: Students encode equations based on their knowledge of arithmetic. Cognitive Science, 28(3), 451-466. https://doi.org/10.1016/j.cogsci.2003.11.002.

Mestre, J. P., Docktor, J. L., Strand, N. E., \& Ross, B. H. (2011). Conceptual problem solving in physics. In J. P. Mestre, \& B. H. Ross (Eds.), Psychology of Learning and Motivation - Advances in Research and Theory (Vol. 55), (pp. 269-298). https://doi.org/10.1016/B978-0-12-387691-1.00009-0.

Michelsen, C. (2015). Mathematical modeling is also physics - interdisciplinary teaching between mathematics and physics in Danish upper secondary education. Physics Education, 50(4), 489-494. https://doi.org/10.1088/0031-9120/50/4/489.

Moss, J., \& Case, R. (1999). Developing children's understanding of the rational numbers: A new model and an experimental curriculum. Journal for Research in Mathematics Education, 30(2), 122-147.

Nakhleh, M. B. (1993). Are our students conceptual thinkers or algorithmic problem solvers? Identifying conceptual students in general chemistry. 
Journal of Chemical Education, 70(1), 52-55. https://doi.org/10.1021/ ed070p52.

Njini, P. (2012). Challenges faced by trainee teachers in the learning of the chain rule: A case study of a midlands teachers training college. Doctoral dissertation. Bindura: Bindura University of Science Education.

Odden, T. O. B., \& Russ, R. S. (2019). Defining sensemaking: Bringing clarity to a fragmented theoretical construct. Science Education, 103, 187-205. https://doi. org/10.1002/sce.21452.

Peled, I., \& Segalis, B. (2005). It's not too late to conceptualize: Constructing a generalized subtraction schema by abstracting and connecting procedures. Mathematical Thinking and Learning, 7(3), 207-230. https://doi.org/10.1207/ s15327833mt10703_2.

Pietrocola, M. (2009). Mathematics as structural language of physical thought. In M. Vicentini, \& E. Sassi (Eds.), Connecting research in physics education with teacher education International Commission on Physics Education.

Polikoff, M. S. (2012). The redundancy of mathematics instruction in US elementary and middle schools. The Elementary School Journal, 113(2), 230-251.

Pospiech, G. (2019). Framework of mathematization in physics from a teaching perspective. Mathematics in Physics Education (pp. 1-33). Cham: Springer.

Potgieter, P., \& Blignaut, P. (2017). Using eye-tracking to assess the application of divisibility rules when dividing a multi-digit dividend by a single digit divisor. In ACM International Conference Proceeding Series, Part F1308. https://doi.org/ 10.1145/3129416.3129427

Quale, A. (2011). On the role of mathematics in physics. Science \& Education, 20(3-4), 359-372. https://doi.org/10.1007/s11191-010-9278-3.

Radmehr, F., \& Drake, M. (2019). Revised Bloom's taxonomy and major theories and frameworks that influence the teaching, learning, and assessment of mathematics: A comparison. International Journal of Mathematical Education in Science and Technology, 50(6), 895-920. https://doi.org/10.1080/0020739X. 2018.1549336.

Ralph, V. R., \& Lewis, S. E. (2018). Chemistry topics posing incommensurate difficulty to students with low math aptitude scores. Chemistry Education Research and Practice, 19(3), 867-884. https://doi.org/10.1039/c8rp00115d.

Redish, E. F. (2004). A theoretical framework for physics education research: Modeling student thinking. In E. Redish, \& M. Vicentini (Eds.), Proceedings of the Enrico Fermi Summer School, Course CLVI. Varenna: Italian Physical Society.

Redish, E. (2005). Changing student ways of knowing: What should our students learn in a physics class. Proceedings of World View on Physics Education 2005 Focusing on Change, New Delhi, 1-13.

Redish, E. F. (2017). Analysing the Competency of Mathematical Modelling in Physics. In: Greczyło T., Dębowska E. (eds) Key Competences in Physics Teaching and Learning. Springer Proceedings in Physics, vol 190. Springer, Cham. https://doi.org/10.1007/978-3-319-44887-9_3.

Redish, E. F., \& Gupta, A. (2009). Making meaning with math in physics: A semantic analysis. GIREP-EPEC \& PHEC 2009, 244.

Redish, E. F., \& Gupta, A. (2010). Making meaning with math in physics: A semantic analysis. In Physics community and cooperation-proceedings of the GIREP-EPEC \& PHEC 2009 international conference, (pp. 1-15).

Redish, E. F., \& Kuo, E. (2015). Language of physics, language of math: Disciplinary culture and dynamic epistemology. Science \& Education, 24(5-6), 561-590. https://doi.org/10.1007/s11191-015-9749-7.

Rittle-Johnson, B., \& Schneider, M. (2015). Developing conceptual and procedural knowledge of mathematics. Oxford Handbook of Numerical Cognition (pp. 1118-1134). Oxford: Oxford University Press.

Rodriguez, J.-M. G., Bain, K., Hux, N. P., \& Towns, M. H. (2019). Productive features of problem solving in chemical kinetics: More than just algorithmic manipulation of variables. Chemistry Education Research and Practice, 20(1), 175-186. https://doi.org/10.1039/C8RP00202A.

Rodriguez, J. M. G., Santos-Diaz, S., Bain, K., \& Towns, M. H. (2018). Using symbolic and graphical forms to analyze students' mathematical reasoning in chemical kinetics. Journal of Chemical Education, 95(12), 2114-2125. https:// doi.org/10.1021/acs.jchemed.8b00584.

Russ, R. S. (2018). Characterizing teacher attention to student thinking: A role for epistemological messages. Journal of Research in Science Teaching, 55(1), 94120. https://doi.org/10.1002/tea.21414.

Russ, R. S., Coffey, J. E., Hammer, D., \& Hutchison, P. (2009). Making classroom assessment more accountable to scientific reasoning: A case for attending to mechanistic thinking. Science Education, 93(5), 875-891. https://doi.org/10. 1002/sce.20320.
Russ, R. S., Scherr, R. E., Hammer, D., \& Mikeska, J. (2008). Recognizing mechanistic reasoning in student scientific inquiry: A framework for discourse analysis developed from philosophy of science. Science Education, 92(3), 499-525. https://doi.org/10.1002/sce.20264.

Sawada, D., Piburn, M. D., Judson, E., Turley, J., Falconer, K., Benford, R., \& Bloom, I. (2002). Measuring reform practices in science and mathematics classrooms: The reformed teaching observation protocol. School Science and Mathematics, 102(6), 245-253. https://doi.org/10.1111/j.1949-8594.2002. tb17883.x.

Schoenfeld, A. H. (1992). Learning to think mathematically: Problem solving, metacognition, and sense making in mathematics. In Handbook for research on mathematics teaching and learning, (pp. 334-370).

Schuchardt, A. M. (2016). Learning biology through connecting mathematics to scientific mechanisms: Student outcomes and teacher supports. Doctoral dissertation. Pittsburgh: University of Pittsburgh.

Schuchardt, A. M., \& Schunn, C. D. (2016). Modeling scientific processes with mathematics equations enhances student qualitative conceptual understanding and quantitative problem solving. Science Education, 100(2), 290-320. https://doi.org/10.1002/sce.21198.

Sevian, H., \& Talanquer, V. (2014). Rethinking chemistry: A learning progression on chemical thinking. Chemistry Education Research and Practice, 15(1), 10-23. https://doi.org/10.1039/c3rp00111c.

Sherin, B. L. (2001). How students understand physics equations. Cognition and Instruction, 19(4), 479-541. https://doi.org/10.1207/S1532690XCl1904_3.

Sherin, B. L. (2006). Common sense clarified: The role of intuitive knowledge in physics problem solving. Journal of Research in Science Teaching, 43(6), 535555. https://doi.org/10.1002/tea.20136.

Smidt, S., \& Weiser, W. (1995). Semantic structures of one-step word problems involving multiplication or division. Educational Studies in Mathematics, 28(1), 55-72. https://doi.org/10.1007/BF01273856.

Smith, M. K., Jones, F. H. M., Gilbert, S. L., \& Wieman, C. E. (2013). The classroom observation protocol for undergraduate STEM (COPUS): A new instrument to characterize university STEM classroom practices. CBE Life Sciences Education, 12, 618-627. https://doi.org/10.1187/cbe.13-08-0154.

Stamovlasis, D., Tsaparlis, G., Kamilatos, C., Papaoikonomou, D., \& Zarotiadou, E. (2005). Conceptual understanding versus algorithmic problem solving: Further evidence from a national chemistry examination. Chemistry Education Research and Practice, 6(2), 104-118. https://doi.org/10.1039/B2RP90001G.

Star, J. R. (2005). Reconceptualizing procedural knowledge. Journal for Research in Mathematics Education, 36(5), 404-411.

Steen, L. A. (2005). The "gift" of mathematics in the era of biology. In L. A. Steen (Ed.), Math and bio 2010: Linking undergraduate disciplines, (pp. 13-25). Washington, DC: The Mathematics Association of America.

Stewart, J. (1983). Student problem solving in high school genetics. Science Education, 67(4), 523-540.

Svoboda, J., \& Passmore, C. (2013). The strategies of modeling in biology education. Science \& Education, 22(1), 119-142. https://doi.org/10.1007/ s11191-011-9425-5.

Taasoobshirazi, G., \& Glynn, S. M. (2009). College students solving chemistry problems: A theoretical model of expertise. Journal of Research in Science Teaching, 46(10), 1070-1089. https://doi.org/10.1002/tea.20301.

Tekkumru-Kisa, M., Stein, M. K., \& Schunn, C. (2015). A framework for analyzing cognitive demand and content-practices integration: Task analysis guide in science. Journal of Research in Science Teaching, 52(5), 659-685. https://doi. org/10.1002/tea.21208.

Thompson, P. W., \& Carlson, M. P. (2017). Variation, covariation and functions: Foundational ways of thinking mathematically. In J. Cai (Ed.), Compendium for research in mathematics education, (pp. 421-456). Reston: National Council of Teachers of Mathematics.

Tsaparlis, G. (2007). Teaching and learning physical chemistry: A review of educational research. In M. D. Ellison, \& T. A. Schoolcraft (Eds.), Advances in teaching physical chemistry, (pp. 75-112). https://doi.org/10.1021/bk-20080973.ch007.

Tuminaro, J., \& Redish, E. F. (2007). Elements of a cognitive model of physics problem solving: Epistemic games. Physical Review Special Topics - Physics Education Research, 3, 020101. https://doi.org/10.1103/PhysRevSTPER.3. 020101.

Uhden, O., Karam, R., Pietrocola, M., \& Pospiech, G. (2012). Modelling mathematical reasoning in physics education. Science \& Education, 21(4), 485-506. https://doi.org/10.1007/s11191-011-9396-6. 
vom Brocke, J., Simons, A., Riemer, K., Niehaves, B., Plattfaut, R., \& Cleven, A. (2015). Standing on the shoulders of giants: Challenges and

recommendations of literature search in information systems research. Communications of the Association for Information Systems, 37, 9. https://doi. org/10.17705/1CAIS.03709.

Von Korff, J., \& Sanjay Rebello, N. (2014). Distinguishing between "change" and "amount" infinitesimals in first-semester calculus-based physics. American Journal of Physics, 82(7), 695-705. https://doi.org/10.1119/1.4875175.

Wells, M., Hestenes, D., \& Swackhamer, G. (1995). A modeling method for high school physics instruction. American Journal of Physics, 63(7), 606-619.

Wigner, E. P. (1960). The unreasonable effectiveness of mathematics in the natural sciences. Communications on Pure and Applied Mathematics, 13(1), 114. https://doi.org/10.1179/030801811X13082311482537.

Wink, D. J., \& Ryan, S. A. C. (2019). The logic of proportional reasoning and its transfer into chemistry. In M. H. Towns, K. Bain, \& J.-M. G. Rodriguez (Eds.), It's Just Math: Research on Students' Understanding of Chemistry and Mathematics (Vol. 1316), (pp. 157-171). https://doi.org/10.1021/bk-2019-1316.ch010.

Wohlin, C. (2014). Guidelines for snowballing in systematic literature studies and a replication in software engineering. ACM International Conference Proceeding Series. https://doi.org/10.1145/2601248.2601268.

\section{Publisher's Note}

Springer Nature remains neutral with regard to jurisdictional claims in published maps and institutional affiliations.

\section{Submit your manuscript to a SpringerOpen ${ }^{\circ}$ journal and benefit from:}

- Convenient online submission

- Rigorous peer review

- Open access: articles freely available online

High visibility within the field

- Retaining the copyright to your article 